\title{
Geoenergy: new concepts for utilization of geo-reservoirs as potential energy sources
}

\author{
Magdalena Scheck-Wenderoth • Dieter Schmeißer • \\ Maria Mutti • Olaf Kolditz • Ernst Huenges • \\ Hans-Martin Schultz • Axel Liebscher • Michaela Bock
}

Received: 7 October 2013/Accepted: 22 October 2013/Published online: 8 November 2013

(c) Springer-Verlag Berlin Heidelberg 2013

\section{Introduction}

The need for new strategies related to the provision of energy calls for new concepts that integrate renewable and unconventional energy sources. At the same time the global energy demand and the need to mitigate global warming require concepts that assure a further but environmentally sustainable use of fossil energy keeping the emission of greenhouse gases, and in particular of $\mathrm{CO}_{2}$, to a minimum. Given these boundary conditions, the concept of geoenergy, not only encompassing the utilization of domestic

\author{
M. Scheck-Wenderoth $(\bowtie) \cdot$ E. Huenges · H.-M. Schultz · \\ A. Liebscher · M. Bock \\ Helmholtz Centre Potsdam GFZ, German Research \\ Centre for Geosciences, Potsdam, Germany \\ e-mail: leni@gfz-potsdam.de \\ M. Scheck-Wenderoth \\ RWTH Aachen University, Aachen, Germany \\ D. Schmeißer \\ Brandenburg University of Technology \\ Cottbus-Senftenberg, Cottbus, Germany \\ M. Mutti \\ Institute of Earth and Environmental Science, \\ University of Potsdam, Potsdam, Germany \\ O. Kolditz \\ Department of Environmental Informatics (ENVINF), \\ Helmholtz Centre for Environmental Research (UFZ), \\ Leipzig, Germany \\ e-mail: EES@ufz.de \\ O. Kolditz \\ Technical University, Dresden, Germany \\ E. Huenges \\ Technical University, Berlin, Germany
}

subsurface reservoirs as potential energy sources but also as potential storage sites for matter or energy, obtains a new relevance. Subsurface reservoirs may be the place from where hot fluids can be produced for the production of geothermal energy, where dynamic or long-term storage of matter or energy can be accomplished or where conventional and unconventional hydrocarbon resources may be located. In a holistic concept of geoenergy, all these aspects need to be integrated to optimally explore and exploit georesources without compromising the environment. This involves the development of not only new technologies for the exploration, utilization and monitoring of the different types of reservoirs but also new concepts for capturing, storing or recycling of $\mathrm{CO}_{2}$ in the process of burning fuels. This establishment of appropriate technologies is still a major challenge in the ecological and sustainable use of geological resources. At the same time, there is an increasing awareness that innovative technologies are needed to allow for an environmentally sound and economically feasible exploitation of geo-reservoirs. This equally applies for traditional and more recent efforts of utilizing the geological underground, e.g. for geothermal energy production, storage of $\mathrm{CO}_{2}$ or other fluids, and the exploitation of shale gas.

This thematic issue assembles papers that report recent advances in the field of geoenergy and illustrates that the combined investigation of the different types of utilization provides synergies and added value. With this volume three technologies-currently under discussion in the context of geoenergy - are addressed (1) geothermal technologies (2) technologies related to capturing, storing and utilizing $\mathrm{CO}_{2}$ and (3) technologies related to the unconventional tapping of resources such as shale gas. Though these concepts and technologies are addressed separately in the individual papers, it is evident that synergies may be obtained due to 
which progress in one of the technologies may be applied to the others. Going through the contents of this volume elucidates that all utilizations of geological reservoirs not only pose similar challenges relating to the exploration, exploitation and utilization but also share similar needs for integrating innovative concepts for monitoring and modelling. Accordingly, the results derived for the individual technologies are transferable, and progress in methodological development may be applicable in equal measure to the utilization of geothermal energy and of shale gas as well as to the use and monitoring of $\mathrm{CO}_{2}$ storage. Likewise, new modelling approaches for the simulation of the involved physico-chemical-biological processes may help to predict the occurrence and properties of potential reservoirs and the changes that may be induced by their utilization.

\section{Geothermal technologies}

An overview of "Geothermal Technologies" is presented by Huenges et al. (2013) in a view article on the current progress and challenges of geothermal energy research. They show a holistic approach addressing the different challenges related to the heat production from depth and energy storage in shallow or deep reservoirs. Some aspects specifically related to geothermal energy systems in shallow aquifers are subsequently presented by Händel et al. (2013), who assess a case study in Austria with a regional modelling approach. Improvements of deep geothermal technologies are reported in the next bundle of papers that describe the research progress relating to the exploration, the engineering and the monitoring as well as to the predictive modelling of deep geothermal reservoirs.

The engineering part starts with a contribution by Feldbusch et al. (2013), who investigate the alteration of fluid properties during the operation of a geothermal plant. Their results from in situ measurements of fluid physicochemical properties at the geothermal research platform Groß Schönebeck provide important information on the changes in fluid properties during production in a highly saline environment. In a complementary technical paper Milsch et al. (2013) describe a new mobile fluid-chemical monitoring unit suitable for operation accompanying acquisition of a set of important process data. In addition to monitoring systems placed at the Earth's surface Reinsch et al. (2013) assess temperature sensing and the other optical fibre-based measurements for monitoring thermal, mechanical and chemical processes down-hole in hot geothermal wells. Such kinds of data were used by Francke et al. (2013) who developed instruments to model the effects of multi-phase brine in geothermal wells and especially interactions of these brines with geothermal system components. A corresponding thermodynamic background of processes with geothermal system components in operation such as heat exchangers are given by Thorade and Saadat (2013).

The following section provides new views not only on how numerical simulations can help in the exploration for geothermal energy but also in predictive assessment of the behaviour of geothermal reservoirs. The papers by Balling et al. (2013) and by Noack et al. (2013) present regional modelling studies assessing the deep geothermal field below different parts of Northern Germany. They demonstrate that regional models integrating complex geology and physical laws of heat transport can reasonably predict temperature distribution at depth. Subsequently Sippel et al. (2013) test the predictive power of such models for the assessment of the deep geothermal field of Berlin, based on which Kastner et al. (2013) explore the deep geothermal potential for this large urban area. The three following papers are dedicated to one of the major challenges in three-dimensional modelling of coupled fluid and heat transport in the subsurface: the proper consideration of faults that may be either conduits or barriers to fluid flow and accordingly will influence the heat transport coupled to fluid motion. Cacace et al. (2013) propose a novel technique for the modelling of fractured carbonate reservoirs applied to a case study from the Molasse Basin in southern Germany. The same approach is applied by Cherubini et al. (2013a, b) who study the first-order influence of fault geometries on the 3D thermal and flow field for simple synthetic models of inclined faults. In a second study, Cherubini et al. (2013a, b) also test a different approach of coupled fluid and heat transport to quantify not only the influence of faults but also of the salt structures for the deep geothermal field of the geothermal research site Groß Schönebeck. Finally, Kaiser et al. (2013) critically review the sensitivity of 3D numerical simulations of coupled fluid and heat transport to the spatial discretisation of the underlying model and find different sensitivities for different mechanisms of heat transport.

\section{Technologies related to capturing, storing and utilizing $\mathrm{CO}_{2}$}

Numerical modelling and adequate modelling strategies are not only required to predict the behaviour of geothermal reservoirs but are also essential tools for any assessment of reservoirs into which $\mathrm{CO}_{2}$ is injected. $\mathrm{CO}_{2}$ storage in deep saline aquifers and deep geothermal reservoirs share similar configurations of physico-chemical properties and processes. However, what is specific to $\mathrm{CO}_{2}$-reservoirs is the presence of at least two coexisting fluid phases in the pore space: a saline aqueous fluid and a $\mathrm{CO}_{2}$ dominated 
fluid. Accordingly predictive modelling of $\mathrm{CO}_{2}$ reservoirs can profit from geothermal simulations but needs to integrate additional processes. Mitiku and Bauer (2013) quantify the different amounts of $\mathrm{CO}_{2}$ that can be stored in a geological anticline reservoir dependent on different possible scenarios of well configuration and reservoir properties. Kempka and Kühn (2013) provide another example for predictive $\mathrm{CO}_{2}$ modelling and validate numerical simulations of $\mathrm{CO}_{2}$ arrival times and reservoir pressure with observations from the Ketzin pilot site in Germany. This natural laboratory allows identifying a variety of technological aspects for safe and sustainable $\mathrm{CO}_{2}$ storage. Fischer et al. (2013) study one of these aspects with laboratory experiments and reactive geochemical modelling-the reactivity of sandstone and siltstone upon $\mathrm{CO}_{2}$ injection using samples from the Ketzin pilot $\mathrm{CO}_{2}$-storage site. Wiese et al. (2013) address another technological aspect of $\mathrm{CO}_{2}$ storage - the monitoring. They report how above-zone well-based hydraulic and geochemical monitoring is applied to the $\mathrm{CO}_{2}$ reservoir in Ketzin to detect possible impacts on the groundwater. Also, biological processes may influence the performance of any reservoir and therefore studies of the deep biological communities are important. It is, however, often a challenge to obtain uncontaminated samples to perform the respective analyses. Pellizzari et al. (2013) present a method involving the use of tracers to assess drill mud penetration depth into sandstone cores during deep drilling and demonstrate the applicability for the $\mathrm{CO}_{2}$ storage site in Ketzin.

Apart from $\mathrm{CO}_{2}$ storage in the reservoir, also the transport of the captured $\mathrm{CO}_{2}$ in the power plant and from the plant to the reservoir are also an important component of Carbon Capture and Storage (CCS) process chain. These transport processes through pipes invoke a fundamentally different behaviour of the $\mathrm{CO}_{2}$ than in the geological reservoir. Accordingly, simulations of this transport need to consider multi-phase and especially turbulent flow physics. Schulz et al. (2013) use a stochastic multi-scale approach for the modelling of $\mathrm{CO}_{2}$ multi-phase flow patterns. In contrast Herzog et al. (2013) use CFD modelling to quantify the dimension of a potential hazard in case of $\mathrm{CO}_{2}$ leakage from transport pipes of high pressurised $\mathrm{CO}_{2}$ released from onshore pipelines. The related material and energy efficiency aspects for $\mathrm{CO}_{2}$ capturing are other important technological challenges. In this context Garkas et al. (2013) present a possible solution for corrosion protection in high-temperature segments of CCS plants. In response to a generally decreasing public acceptance of the classical CCS concept, at least in Germany, alternative solutions to storing $\mathrm{CO}_{2}$ in the subsurface are sought. Here the concept of carbon capture and utilization (CCU) may provide a viable solution invoking the utilization of the captured $\mathrm{CO}_{2}$ in synthetic fuel generation. In this "power to gas" approach $\mathrm{H}_{2}$ generated by excess wind or solar power reacts with $\mathrm{CO}_{2}$ to form methane. This so-called Sabatier-based $\mathrm{CO}_{2}$ methanation requires a catalytic conversion for, which Müller et al. (2013) present impressive new experimental results in this volume. Complementary, Städter et al. (2013) and Das et al. (2013) report analytical progress related to the evaluation of $\mathrm{NiO} / \mathrm{SiO}_{2}$-catalysts and $\mathrm{TiO}_{2}$ films.

\section{Unconventional reservoirs and hydraulic fracturing}

The third geoenergy-related theme that may considerably contribute to future energy supply from domestic resources is the utilization of unconventional reservoirs. The latter contain oil and/or gas but are too tight to liberate these hydrocarbons without artificially increasing the permeability by fracturing. Similar to deep geothermal reservoirs or $\mathrm{CO}_{2}$-storage sites at first an exploration concept is required to find out if such reservoirs locally exist, and if this is the case, concepts of sustainable utilization must ensure environmental safety. Hammes et al. (2013) explore the unconventional reservoir potential of the Upper Permian Zechstein Formation in Northern Germany. They conclude from shelf to basin sequence stratigraphic and sedimentological evaluation that new exploration possibilities locally exist with potential for shale gas/oil and hybrid unconventional plays. Kerschke and Schulz (2013) analyse the shale gas potential of three other formations in North Germany: the Tournaisian, Visean, and Namurian Black Shales and also find indications for local potential. In particular shale gas has received enormous attention by the public recently and early mistakes in the production of shale gas have reduced public acceptance severely. To facilitate objective discussion of the chances and risks of this type of fossil energy, Hübner et al. (2013) introduce an internet platform gathering fact-based communication about shale gas: the Shale Gas Information Platform (SHIP). This knowledge exchange platform follows basic principles of being science based, transparent and balanced. Such type of information may become the basis for future public discussion for other aspects of geoenergy.

A prominent example for a highly debated aspect of geoenergy including public participation is "hydraulic fracturing" which is taken up in this volume in a succession of five papers. Lange et al. (2013) and Kissinger et al. (2013) address the issue of hydraulic fracturing in unconventional gas reservoirs in two parts with special focus on the risks in the geological system. The next paper by Gordalla et al. (2013) is addressing the question whether hydraulic fracturing is a toxicological threat for groundwater, whereas Olsson et al. (2013) present a view on the 
composition, treatment and concerns related to hydraulic fracturing wastewater. A further view on the topic is given by Riedl et al. (2013) who propose a strategy for the ecotoxicological assessment of fracturing fluids.

Acknowledgments We thank the Federal Ministry of Education and Research (BMBF) of Germany for funding a large part of the work presented in this this volume in the program "Spitzenforschung in den neuen Ländern" (BMBF grants GeoEn and Influins). We are also grateful to the Helmholtz Association for the program-oriented funding (POF) of the renewable energy research in the frame of the POF-2 (2010-2014). We deeply acknowledge the voluntary work of all reviewers (more than 100) for critical and constructive discussion of the contributions based on which the quality of the thematic issue on new concepts for utilization of geo-reservoirs as potential energy sources could be significantly improved.

\section{References}

Balling P, Maystrenko Y, Scheck-Wenderoth M (2013) The deep thermal field of the Glueckstadt Graben. Environ Earth Sci. doi:10.1007/s12665-013-2750-z

Cacace M, Blöcher G, Watanabe N, Moeck I, Börsing N, ScheckWenderoth M, Kolditz O, Huenges E (2013) Modelling of fractured carbonate reservoirs - outline of a novel technique via a case study from the Molasse Basin, southern Bavaria (Germany). Environ Earth Sci. doi:10.1007/s12665-013-2402-3

Cherubini Y, Cacace M, Blöcher G, Scheck-Wenderoth M (2013a) Impact of single inclined faults on the fluid flow and heat transport: results from 3D finite element simulations. Environ Earth Sci. doi:10.1007/s12665-012-2212-z

Cherubini Y, Cacace M, Scheck-Wenderoth M, Moeck I, Lewerenz B (2013b) Controls on the deep thermal field-implications from 3D numerical simulations for the geothermal research site Groß Schönebeck. Environ Earth Sci. doi:10.1007/s12665-013-2519-4

Das C, Tallarida M, Schmeißer D (2013) Linear Dichroism in ALD layers of $\mathrm{TiO}_{2}$. Environ Earth Sci. doi:10.1007/s12665-0132836-7

Feldbusch E, Regenspurg S, Banks J, Milsch H, Saadat A (2013) Alteration of fluid properties during the initial operation of a geothermal plant-results from in-situ measurements in Groß Schönebeck. Environ Earth Sci. doi:10.1007/s12665-013-2409-9

Fischer S, Liebscher A, De Lucia M, Hecht L (2013) Reactivity of sandstone and siltstone samples from the Ketzin pilot $\mathrm{CO} 2$ storage site - Laboratory experiments and reactive geochemical modeling. Environ Earth Sci. doi:10.1007/s12665-013-2669-4

Francke H, Saadat A, Kraume M (2013) Thermal-hydraulic measurements and modelling of the brine circuit in a geothermal well. Environ Earth Sci. doi:10.1007/s12665-013-2612-8

Garkas W, Weiss S, Wang Q (2013) (Cr1-xAlx)N as a candidate for corrosion protection in high temperature segments of CCS plants. Environ Earth Sci. doi:10.1007/s12665-013-2646-y

Gordalla B, Ewers U, Frimmel FH (2013) Hydraulic fracturing-a toxicological threat for groundwater and drinking water? Environ Earth Sci. doi:10.1007/s12665-013-2672-9

Händel F, Liedl R, Fank J, Rock G (2013) Regional modeling of geothermal energy systems in shallow aquifers-the Leibnitzer Feld case study (Austria). Environ Earth Sci. doi:10.1007/ s12665-013-2469-x

Hammes U, Krause M, Mutti M (2013) Unconventional Reservoir potential of the upper permian Zechstein formation: a shelf to basin sequence stratigraphic and sedimentological evaluation of carbonates and organic-rich mudrocks Northern Germany. Environ Earth Sci. doi:10.1007/s12665-013-2724-1

Herzog N, Gorenz P, Egbers C (2013) CFD modeling of high pressurized $\mathrm{CO} 2$ released from onshore pipeline leakages. Environ Earth Sci. doi:10.1007/s12665-013-2536-3

Hübner A, Horsfield B, Kapp I (2013) Fact-based communication about shale gas: the Shale Gas Information Platform SHIP. Environ Earth Sci. doi:10.1007/s12665-013-2504-y

Huenges E, Kohl T, Kolditz O, Bremer J, Scheck-Wenderoth M (2013) Geothermal energy systems-research demand for sustainable and domestic energy provision. Environ Earth Sci (in revision). doi:10.1007/s12665-013-2881-2

Kaiser BO, Cacace M, Scheck-Wenderoth M (2013) 3D coupled fluid and heat transport simulations of the Northeast German Basin and their sensitivity to the spatial discretization: different sensitivities for different mechanisms of heat transport. Environ Earth Sci. doi:10.1007/s12665-013-2249-7

Kastner O, Sippel J, Scheck-Wenderoth M, Huenges E (2013) The deep geothermal potential of the Berlin area. Environ Earth Sci. doi:10.1007/s12665-2670-y

Kempka T, Kühn M (2013) Numerical simulations of CO2 arrival times and reservoir pressure coincide with observations from the Ketzin pilot site. Germany. Environ Earth Sci. doi:10.1007/ s12665-013-2614-6

Kerschke D, Schulz H-M (2013) The shale gas potential of Tournaisian, Visean, and Namurian Black Shales in North Germany: baseline parameters in a geological context. Environ Earth Sci. doi:10.1007/s12665-013-2745-9

Kissinger A, Helmig R, Ebigbo A, Class H, Lange T, Sauter M, Heitfeld M, Klünker J, Jahnke W (2013) Hydraulic fracturing in unconventional gas reservoirs-risks in the geological system, part 2. Environ Earth Sci. doi:10.1007/s12665-013-2578-6

Lange T, Sauter M, Heitfeld M, Schetelig K, Jahnke W, Kissinger A, Helmig R, Ebigbo A, Class H (2013) Hydraulic fracturing in unconventional gas reservoirs-risks in the geological system, Part 1. Environ Earth Sci. doi:10.1007/s12665-013-2803-3

Milsch H, Giese R, Poser M, Kranz S, Feldbusch E, Regenspurg S (2013) Technical paper: FluMo-a mobile fluid-chemical monitoring unit for geothermal plants. Environ Earth Sci. doi:10. 1007/s12665-013-2408-x

Mitiku AB, Bauer S (2013) Optimal use of a dome shaped anticline structure for $\mathrm{CO} 2$ storage: A case study in the North German sedimentary basin. Environ Earth Sci. doi:10.1007/s12665-013$2580-\mathrm{z}$

Müller K, Städter M, Rachow F, Hoffmannbeck D, Schmeißer D (2013) Sabatier- based $\mathrm{CO}_{2}$-methanation by catalytic conversion. Environ Earth Sci. doi:10.1007/s12665-013-2609-3

Noack V, Scheck-Wenderoth M, Cacace M, Schneider M (2013) Influence of fluid flow on the regional thermal field: results from 3D numerical modelling for the area of Brandenburg (North German Basin). Environ Earth Sci. doi:10.1007/s12665-0132438-4

Olsson O, Weichgrebe D, Rosenwinkel K-H (2013) Hydraulic fracturing wastewater in Germany: composition, treatment, concerns. Environ Earth Sci. doi:10.1007/s12665-013-2535-4

Pellizzari L, Neumann D, Alawi M, Voigt D, Norden B, Würdemann H (2013) The use of tracers to assess drill mud penetration depth into sandstone cores during deep drilling: method development and application. Environ Earth Sci. doi:10.1007/s12665-013-2715-2

Reinsch T, Henninges J, Ásmundsson R (2013) Thermal, mechanical and chemical influences on the performance of optical fibres for distributed temperature sensing in a hot geothermal well. Environ Earth Sci. doi:10.1007/s12665-013-2248-8

Riedl J, Rotter S, Faetsch S, Schmitt-Jansen M, Altenburger R (2013) Proposal for applying a component-based mixture approach for 
ecotoxicological assessment of fracturing fluids. Environ Earth Sci. doi:10.1007/s12665-013-2320-4

Schulz FT, Glawe C, Kerstein AR, Schmidt H (2013) Toward modeling of $\mathrm{CO} 2$ multi-phase flow patterns using a stochastic multi-scale approach. Environ Earth Sci. doi:10.1007/s12665-013-2461-5

Sippel J, Fuchs S, Cacace M, Kastner O, Huenges E, Scheck-Wenderoth M (2013) Deep 3D thermal modelling for the city of Berlin (Germany). Environ Earth Sci. doi:10.1007/s12665-013-2679-2

Städter M, Richter M, Rachow F, Müller K, Schmeißer D (2013) Ambient pressure thermal desorption spectroscopy (AP-TDS) of
$\mathrm{NiO} / \mathrm{SiO}_{2}$-catalysts. Environ Earth Sci. doi:10.1007/s12665-0132835-8

Thorade M, Saadat A (2013) Partial derivatives of thermodynamic state properties for dynamic simulation. Environ Earth Sci. doi:10.1007/s12665-013-2394-Z

Wiese B, Zimmer M, Nowak M, Pilz P (2013) Well-based hydraulic and geochemical monitoring of the $\mathrm{CO} 2$ reservoir in Ketzin Germany. Environ Earth Sci. doi:10.1007/s12665-013-2744-x 